\title{
Numerical modeling of the CN spectral emission of the Stardust re-entry vehicle
}

\author{
Alexandre Martin* \\ Department of Mechanical Engineering, University of Kentucky, Lexington, KY, 40506, USA \\ Erin D. Farbar ${ }^{\dagger}$ and Iain D. Boyd ${ }^{\ddagger}$ \\ Department of Aerospace Engineering, University of Michigan, Ann Arbor, MI, 48109, USA
}

\begin{abstract}
Re-entry vehicles designed for space exploration are usually equipped with thermal protection systems made of ablative material. In order to properly model and predict the aerothermal environment of the vehicle, it is imperative to account for the gases produced by ablation processes. In the case of charring ablators, where an inner resin is pyrolyzed at a relatively low temperature, the composition of the gas expelled into the boundary layer is complex and may lead to thermal chemical reactions that cannot be captured with simple flow chemistry models. In order to obtain better predictions, an appropriate gas flow chemistry model needs to be included in the CFD calculations. Although more arc-jet experimental data is becoming available for model comparison, very little flight data exists for comparison and validation. However, because of the observation mission campaign led by NASA, data is available for the re-entry of the Stardust sample return vehicle, which employed a heat shield constructed of phenolic impregnated carbon ablator (PICA). Using a recently developed chemistry model for ablating carbon-phenolic-in-air species, a CFD calculation of the Stardust re-entry at $71 \mathrm{~km}$ is presented. The result demonstrates the need to account for different species in the flow field than the ones composing the pyrolysis gas. It is also shown that the main heat flux reduction phenomenon is through mass diffusion, and not through translational-rotational conduction, as is the case at higher altitude. The flow field solutions are also used to generate nonequilibrium radiation spectra, which are compared to the experimental data obtained during Stardust re-entry by the Echelle instrument. The predicted emission from the CN lines compares quite well with the experimental results, demonstrating the validity of the current approach.
\end{abstract}

\section{Nomenclature}

Symbols

$B^{\prime} \quad$ Non dimensional ablation rate

$D \quad$ Mass diffusion coefficient

Kn Knudsen number

$\dot{m} \quad$ Mass flow rate

$p \quad$ Pressure

$\begin{array}{ll}T & \text { Temperature } \\ U, v & \text { Velocity } \\ Y & \text { Mass fraction } \\ \eta & \text { Distance normal to the wall } \\ \rho & \text { Mass density }\end{array}$

Subscripts

$\begin{array}{ll}c & \text { Char } \\ v e & \text { Vibrational-Electron-Electronic }\end{array}$

$g \quad$ Gas blown

tr Translational-Rotational

nc Next to the wall

$s \quad$ Species

*Assistant Professor, AIAA Senior Member

$\dagger$ Research Associate, AIAA Member

${ }^{\ddagger}$ James E. Knott Professor of Engineering, Fellow AIAA. 


\section{Introduction}

The Thermal Protection System (TPS) of a re-entry vehicle is one of the key components of its design. The materials used for the TPS can be classified into two main categories: ablative materials, such as the ones used on the Apollo missions, and non-ablative materials, such as the ceramic tiles used on the Space Shuttle. The former can also be divided into two sub-categories: charring (also know as pyrolyzing) and non-charring ablators. The theory behind the use of ablators is quite simple: the energy absorbed by the removal of material from the surface is not used to heat the TPS, thus keeping the vehicle at a relatively "cold" temperature. In the case of charring ablators, the ablative material is a resin which fills the pores of a carbon matrix. Although the matrix may ablate, it usually does not, thus preserving the original geometry of the aerodynamic surface during re-entry.

In order to properly model the heating rates at the surface of the vehicle, the ablating boundary condition must take into account many phenomena: surface recession, wall temperature, blowing rates, gas composition, surface chemistry, etc. However, to account for the effects of the pyrolysis gas on the vehicle, the chemistry model of the flow field must include the reactions associated with the presence of this gas. Because ablation coupling is becoming an increasingly important research topic, ${ }^{1-7}$ the development of an accurate, yet usable, chemistry model is of great importance. Models have been proposed in the past ${ }^{8-10}$ but important reactions were not included, and some of the reaction rates were inappropriate or simply outdated.

Recently, a more complete model was proposed, ${ }^{11}$ which includes an extensive set of kinetic rates, taken from the combustion community. The model was reduced using 0-D sensitivity analysis over a parameter space relevant to the re-entry conditions that such a material would be exposed to. It was established that such a model was necessary to study carbon-phenolic TPS through a review of past models, which gave a wide range of results, especially when radiative heat transfer calculations were performed. ${ }^{12}$ The reduced model was later integrated into the hypersonic Computational Fluid Dynamics (CFD) code LeMANS. As a test case, results were obtained at various trajectory points of the Stardust re-entry vehicle, and the importance of accounting for ablation in flow field chemistry was highlighted.

This paper focuses on the $71 \mathrm{~km}$ trajectory point, at which measurements of the spectrally resolved radiative emission from the shock heated gases around the Stardust vehicle were made using the Echelle instrument. This test-case is chosen so that the computed results can be processed using the NEQAIR (version 99d) radiation code, ${ }^{13}$ and then compared to the experimental data gathered by the Echelle instrument.

\section{Chemistry model}

The chemistry model used in this analysis has been developed and optimized for vehicles equipped with ablative heat shields composed of PICA, re-entering in a $\mathrm{N}_{2}-\mathrm{O}_{2}$ atmosphere. ${ }^{11,14}$ The species and reaction mechanisms used in the model were carefully selected using a material response analysis. The corresponding kinetic chemistry rates were taken from the GRI-MECH model, and then reduced using a sensitivity analysis. ${ }^{11,12,14}$ The reduced model contains 38 species and 158 reaction rates. The selected species can be grouped into three categories; the air species:

$$
\mathrm{N}_{2}, \mathrm{O}_{2}, \mathrm{NO}, \mathrm{N}, \mathrm{O}, \mathrm{N}_{2}^{+}, \mathrm{O}_{2}^{+}, \mathrm{NO}^{+}, \mathrm{N}^{+}, \mathrm{O}^{+}, \mathrm{e}
$$

the surface species:

$$
\mathrm{H}_{2}, \mathrm{CO}, \mathrm{CH}_{4}, \mathrm{H}_{2} \mathrm{O}, \mathrm{CO}_{2}, \mathrm{OH}, \mathrm{C}_{2} \mathrm{H}_{2}, \mathrm{HCN}, \mathrm{C}_{2} \mathrm{H}, \mathrm{C}_{3}, \mathrm{CN}
$$

and the reacting species:

$$
\begin{gathered}
\mathrm{H}, \mathrm{NH}, \mathrm{HO}_{2}, \mathrm{H}_{2} \mathrm{O}_{2}, \mathrm{HCO}, \mathrm{C}, \mathrm{C}_{2}, \mathrm{CH}, \mathrm{CH}_{2}, \mathrm{CH}_{3}, \mathrm{NCO}, \mathrm{HNO} \\
\mathrm{CO}^{+}, \mathrm{CN}^{+}, \mathrm{C}^{+}, \mathrm{H}^{+}
\end{gathered}
$$

The reaction mechanisms and kinetics rates are listed in Ref. 12. The model has been validated with multiple zero-dimensional simulations performed using the CHEMKIN ${ }^{15}$ package, and compared to available experimental data that are representative of an ablative boundary layer during hypersonic re-entry. ${ }^{11}$ 


\section{LeMANS: an unstructured three-dimensional Navier-Stokes solver for hypersonic nonequilibrium aerothermodynamics}

The hypersonic aerothermodynamic CFD code used to analyze the chemistry model is LeMANS, a finite volume Navier-Stokes solver currently being developed at The University of Michigan. ${ }^{16-19}$ The code assumes that the rotational and translational energy modes of all species can be described by their respective temperatures $T_{r}$ and $T$, and that the vibrational energy mode and electronic energy mode of all species, as well as the free electron kinetic energy, can be described by a single temperature, $T_{v e} .{ }^{20}$ The viscous stresses are modeled assuming a Newtonian fluid, using Stokes' hypothesis, and the species mass diffusion fluxes are modeled using a modified version of Fick's law. Mixture transport properties are calculated using one of two models; the first uses Wilke's semi-empirical mixing rule with species viscosities calculated using Blottner's model and species thermal conductivities determined using Eucken's relation, and the other uses Gupta's mixing rule with species viscosities and thermal conductivities calculated using non-coulombic/coulombic collision cross section data. Heat fluxes are modeled according to Fourier's law for all temperatures. Finally, the source terms of the species conservation equations are modeled using a standard finite-rate chemistry model for reacting air in conjunction with Park's two-temperature model to account for thermal nonequilibrium effects on the reaction rates.

The code has the capability to handle meshes containing any mix of hexahedra, tetrahedra, prisms and pyramids in 3D, or triangles and quadrilaterals in 2D. Numerical fluxes between the cells are discretized using a modified Steger-Warming Flux Vector Splitting scheme, which has low dissipation and is appropriate to calculate boundary layers. A point or line implicit method is used to perform the time integration. The code has been extensively validated against experimental data, and has also been compared to other similar codes such as NASA Ames' DPLR ${ }^{21}$ and NASA Langley's LAURA. ${ }^{22}$

To account for the coupling between the flow field and the material response, the effects of ablation are added to the CFD code; therefore, a modification to the surface boundary condition is necessary. The physical values at the wall are obtained by solving the conservation of momentum equation:

$$
p_{n c}+\rho_{n c} v_{n c}^{2}=p_{w}\left(\rho_{w}, T_{w}\right)+\rho_{w} v_{w}^{2}
$$

as well as the species surface mass balance equation:

$$
\rho_{w} D_{w s} \frac{\partial Y_{w s}}{\partial \eta}=\dot{m}\left(Y_{g_{s}}-Y_{w s}\right)
$$

The surface energy balance equation does not need to be solved in the present analysis as the wall temperature, blowing rates and blowing species are imposed and not calculated.

Once values are computed for the primitive variables, the conservative quantities in the ghost cells of the boundary are set such that the flux across the wall is the required blowing flux. This blowing boundary condition has been tested over a wide range of blowing rates, assuring the robustness of the implementation. Following the same methodology for the verification and validation of NASA Ames' DPLR code ${ }^{23}$ and NASA Langley's LAURA code ${ }^{24}$ the blowing boundary of LeMANS has also been verified and validated. ${ }^{7,25}$

\section{Test-case: Stardust re-entry vehicle at $71 \mathrm{~km}$}

\section{A. Problem description}

In order to evaluate and validate the model used in LeMANS, the forebody of the Stardust return capsule is modeled at $42 \mathrm{~s}$ into the re-entry. ${ }^{26}$ This re-entry point is chosen because it is well into the continuum region where the Navier-Stokes equations are valid, and spectral emission data obtained by the Echelle instrument is available. The geometry and mesh are presented in Fig. 1 and the flow and surface parameters are given in Tables 1 and 2, respectively. To complete the chemistry model described earlier, Gibb's Free Energy is used to calculate the equilibrium constants needed for the backward reaction rates, and the transport properties are calculated from Lennard-Jones potentials, using CHEMKIN,${ }^{15}$ to produce temperature dependent viscosity curve fits for each species.

The values used for the surface temperature, blowing rates and gas composition are obtained with an uncoupled approach, using a combination of three NASA software tools. First, the aeroheating environment is calculated using DPLR. ${ }^{27}$ The heat transfer coefficient, the surface pressure and the freestream enthalpy 


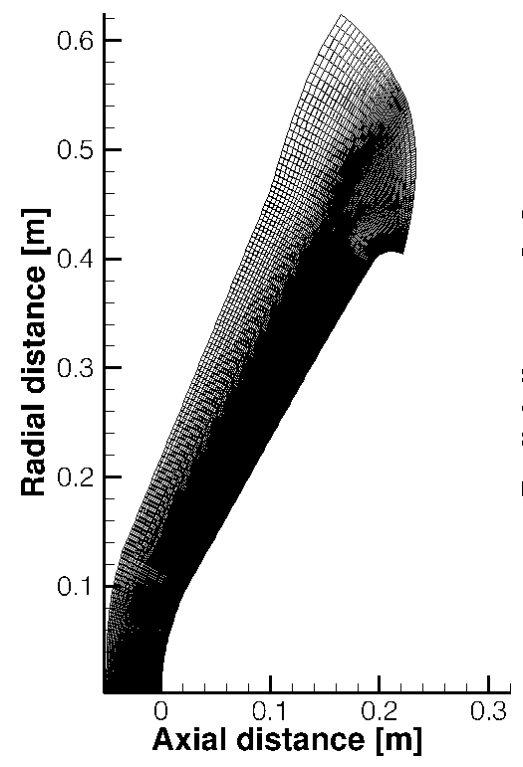

(a) Geometry and overall mesh

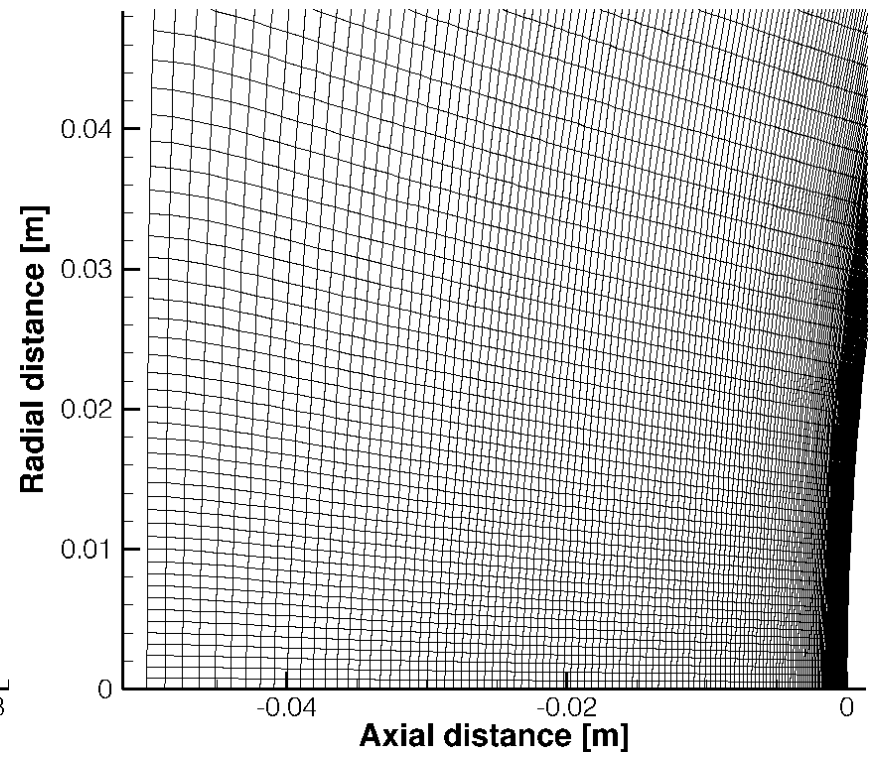

(b) Stagnation region mesh

Figure 1. Geometry and mesh of the Stardust re-entry capsule, used for the chemistry model comparison

Table 1. Free stream conditions for the Echelle period of the trajectory of the Stardust re-entry vehicle

\begin{tabular}{cccccccc}
\hline \hline $\begin{array}{c}\text { Time } \\
{[\mathrm{s}]}\end{array}$ & $\begin{array}{c}\text { Altitude } \\
{[\mathrm{km}]}\end{array}$ & $\begin{array}{c}U_{\infty} \\
{[\mathrm{km} / \mathrm{s}]}\end{array}$ & $\begin{array}{c}T_{\infty} \\
{[\mathrm{K}]}\end{array}$ & $\begin{array}{c}\rho_{\infty} \\
{\left[\mathrm{kg} / \mathrm{m}^{3}\right]}\end{array}$ & $Y_{N_{2}}$ & $Y_{O_{2}}$ & $\mathrm{Kn}$ \\
\hline 42 & 71.2 & 12.1 & 222. & $5.55 \times 10^{-4}$ & 0.763 & 0.237 & 0.00145 \\
\hline \hline
\end{tabular}

Table 2. Wall condition at the stagnation point for the Echelle period of the trajectory of the Stardust re-entry vehicle

\begin{tabular}{ccccccc}
\hline \hline $\begin{array}{c}\text { Time } \\
{[\mathrm{s}]}\end{array}$ & $\begin{array}{c}T_{w} \\
{[\mathrm{~K}]}\end{array}$ & $\begin{array}{c}\dot{m}_{w} \\
{\left[\mathrm{~kg} / \mathrm{m}^{2} / \mathrm{s}\right]}\end{array}$ & $Y_{N_{2}}$ & $Y_{C O}$ & $Y_{H_{2}}$ & $Y_{\mathrm{H}_{2} O}$ \\
\hline 42 & 3240. & 0.0453 & $6.75 \times 10^{-1}$ & $1.23 \times 10^{-1}$ & $5.76 \times 10^{-3}$ & $5.23 \times 10^{-2}$ \\
\hline \hline \multicolumn{7}{c}{} \\
\hline \hline $\begin{array}{c}\text { Time } \\
{[\mathrm{s}]}\end{array}$ & $Y_{O H}$ & $Y_{O}$ & $Y_{\mathrm{CO}_{2}}$ & $Y_{N O}$ & $Y_{O_{2}}$ & $Y_{N}$ \\
\hline 42 & $3.30 \times 10^{-2}$ & $3.68 \times 10^{-2}$ & $2.70 \times 10^{-2}$ & $1.74 \times 10^{-2}$ & $2.99 \times 10^{-2}$ & 0.00 \\
\hline \hline
\end{tabular}


are then used in the material response code, FIAT. ${ }^{28}$ The pressure and the non-dimensionalized ablation rate, $\mathrm{B}_{g}^{\prime}$ and $\mathrm{B}_{c}^{\prime}$, values predicted by FIAT are then extracted and input to the Multicomponent Ablation Thermochemistry (MAT) code. ${ }^{29}$ When given this information, MAT calculates back from the $\mathrm{B}^{\prime}$ tables the species mole fractions according to JANNAF information corresponding to the wall temperature predicted by FIAT. This procedure therefore provides input values for blowing rates, wall temperature and equilibrium species composition. It is to be noted that the equilibrium condition is computed while accounting for the boundary layer edge gas (air) and the surface material (carbon), and therefore accounts for surface ablation. The downside of this procedure is that mass is introduced at the surface as the boundary layer edge gas is considered to be injected at the surface. However, at this altitude the added mass is negligible, since the blowing rate is less than $1 \%$ of the freestream mass flux.

The values obtained through this procedure are only calculated at the stagnation point and are expected to be significantly lower elsewhere on the forebody of the vehicle. To reflect this, a temperature profile is obtained using a fully radiative equilibrium boundary condition at the wall, without ablation. The surface temperature profile is then normalized and re-applied for the ablating wall simulation, multiplied by the surface temperature at the stagnation point that is listed in Table 2. This method has been proven to give a good estimate of the surface conditions. ${ }^{26}$ For the blowing rate, a linear relation between the temperature and the mass flux is derived using the second and third columns of Table 2, and applied proportionally using the normalized surface temperature profile. The values for those two parameters are presented in Fig. 2.

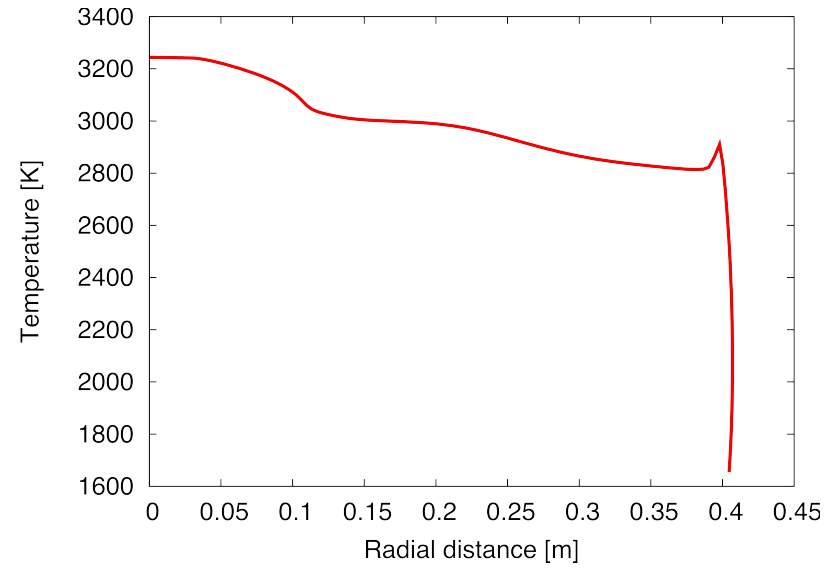

(a) Surface temperature

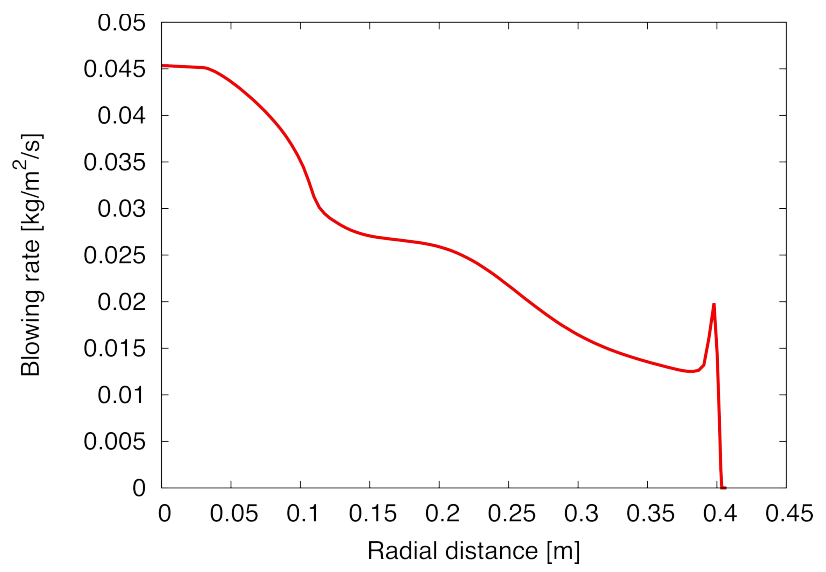

(b) Surface blowing rate

Figure 2. Surface temperature and blowing rates at $42 \mathrm{~s}(71 \mathrm{~km})$ for Stardust

\section{B. Results}

\section{Convective heat flux}

The convective heat flux obtained with the ablative boundary condition, using the proposed chemistry model, is presented in Fig. 3. As expected, the heat flux is significantly reduced when compared to the radiative equilibrium heat flux, also presented in that figure. As can be seen in Fig. 4, most of the heat reduction comes in the form of the mass diffusion term. This is a different phenomenon than that observed at higher altitude ${ }^{14}$ where the majority of the reduction in heat flux occurred through the translational-rotational term. A decrease of this latter term is still observed, of approximately the same magnitude as at the higher altitude trajectory point, but it is no longer the dominating factor. The reduction in the mass diffusion term is explained by the increased blowing rates which causes the mixing region to be thicker, thus reducing the species gradients near the wall. The reduction of the translational-rotational conduction term is caused by a slight modification of the temperature gradients, due to the fact that the shock is pushed away from the surface by the blowing at the surface. Additionally, the change in boundary layer composition causes a modification of the thermal conductivity of the gas, which also acts to reduce this term. 


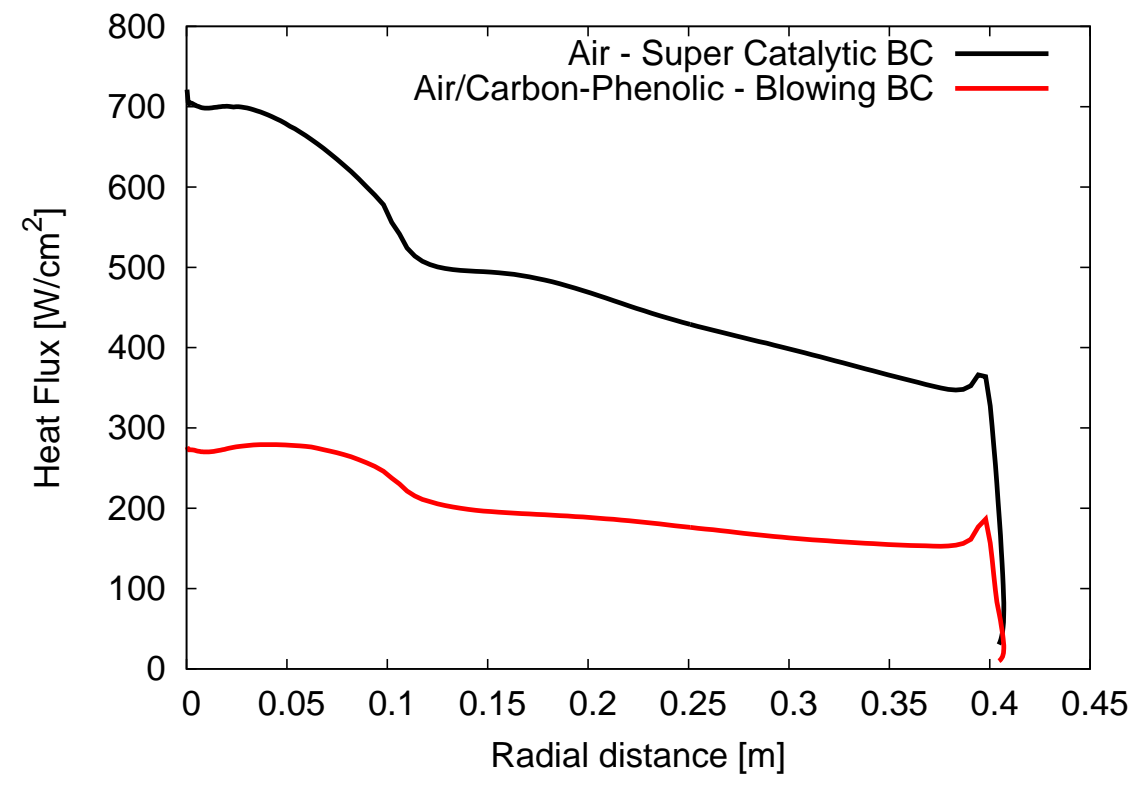

Figure 3. Heat fluxes at the surface of the Stardust re-entry vehicle at 42 seconds $(71 \mathrm{~km})$, computed using the an air-only chemistry model in the flow field with supercatalytic boundary conditions, and the carbonphenolic-in-air chemistry model, with a blowing boundary condition

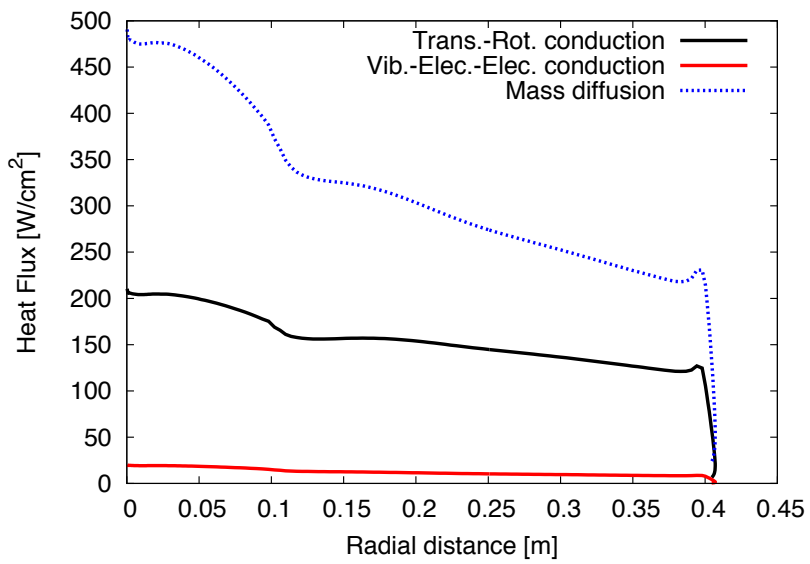

(a) Air-only chemistry; supercatalytic boundary condition

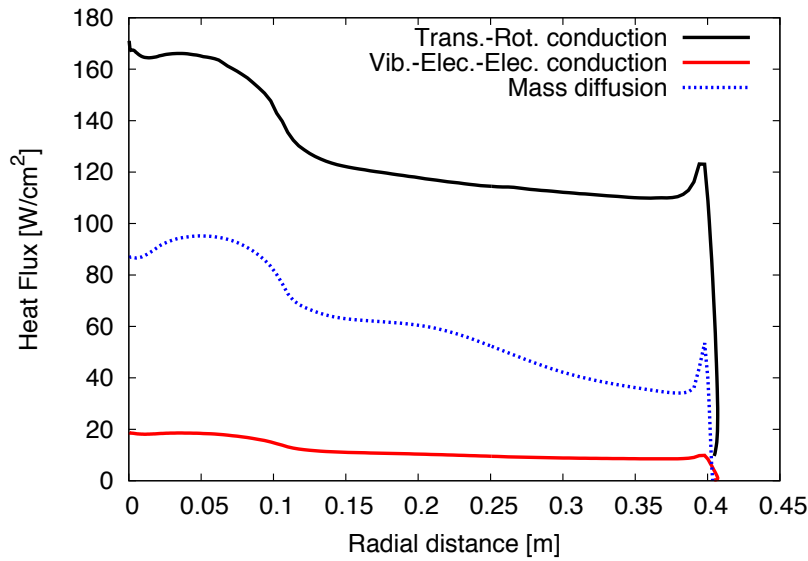

(b) Carbon-phenolic-in-air chemistry; blowing boundary condition

Figure 4. Individual heat flux components 


\section{Species concentrations}

The species composition along the stagnation line is presented in Fig. 5. It is interesting to note in Fig. 5b) that most of the $\mathrm{C}-\mathrm{H}$ blowing species $\left(\mathrm{CO}_{2}, \mathrm{H}_{2}, \mathrm{OH}\right.$ and $\left.\mathrm{H}_{2} \mathrm{O}\right)$ are destroyed almost immediately once they enter the flow, although $\mathrm{CO}$ remains in high concentration. This species is important since it is itself a strong radiator, but more importantly, it is the main source of $\mathrm{CN}$ through the $\mathrm{CO} / \mathrm{CN}$ exchange reaction, and $\mathrm{CN}$ is one of the strongest radiators at re-entry conditions. In Fig. 5c), it can be seen that most blowing species are transformed into atomic species ( $\mathrm{H}$ and $\mathrm{C}$ ), as they are present in high concentrations near the boundary. This figure also shows that $\mathrm{CN}$ is also present in great quantities. It is also interesting to note, in that same figure, that the concentration of HNO is relatively high near the shock; this species was neglected in past models. ${ }^{8-10}$ Finally, Fig. 5d) presents the species which are not present in a significant concentration (species that had a number density less than the machine precision are not shown). Although it might be tempting to discard them, they remain important since they start to appear in greater concentration at other re-entry conditions (i.e. other altitudes). The same calculations were performed for the other trajectory points, as presented in Ref. 11, and although some differences are noticeable, the general conclusions remain the same.

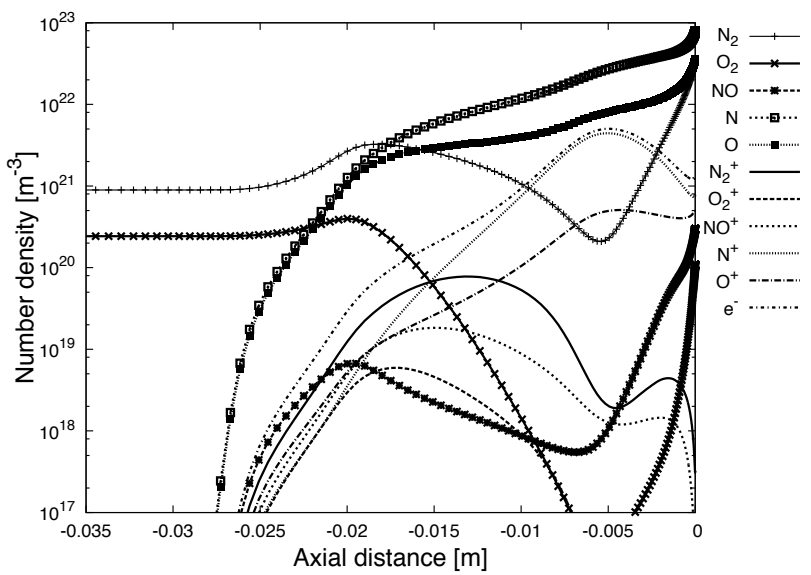

(a) Air species

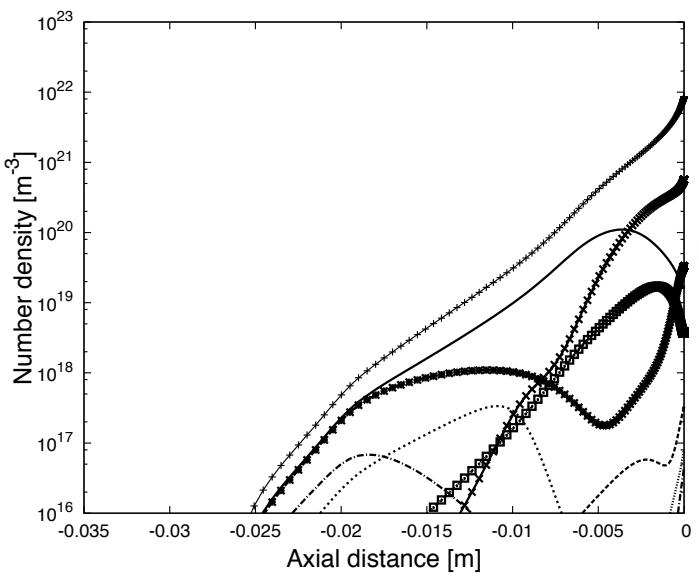

(c) High concentration species

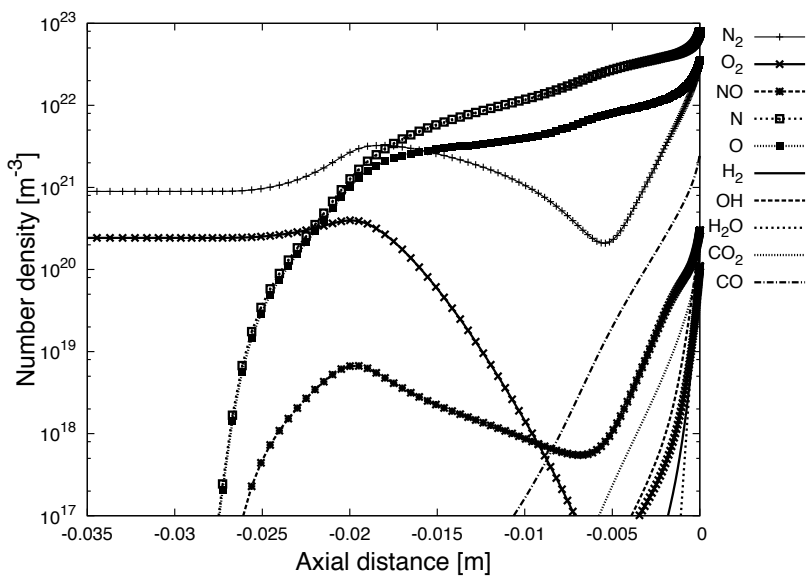

(b) Surface blowing species

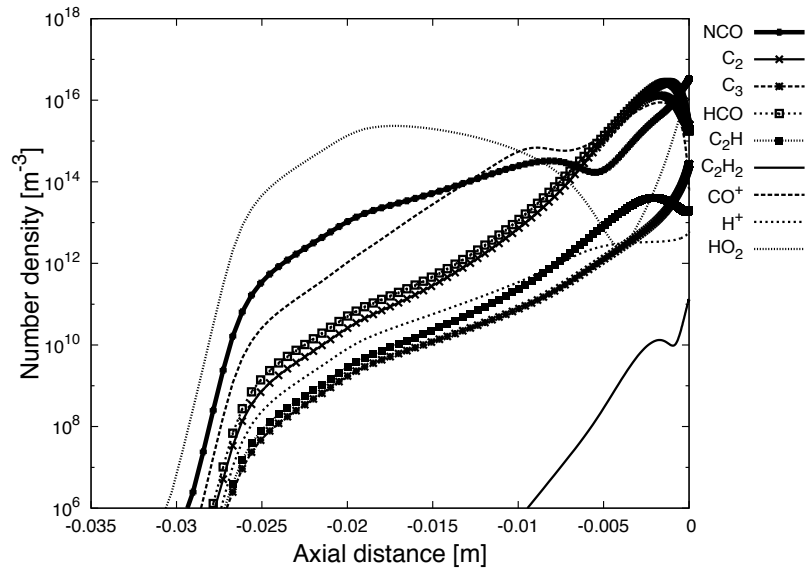

(d) Low concentration species

Figure 5. Species concentrations along the stagnation line for the Stardust vehicle at $42 \mathrm{~s}$ into re-entry

The number density of the species identified as important in Fig. 5 are plotted over the whole computational domain in Figs. 6 to 8. In Fig. 6, it is interesting to notice that $\mathrm{H}$ and $\mathrm{C}$ remain at a fairly high concentration throughout the entire shock layer. As for $\mathrm{HNO}$ and $\mathrm{NH}$, they are both essentially created in the shock region, and are present in substantial concentration. Both of these species were previously neglected in other carbon-phenolic-in-air chemistry models. The distribution of the CO and CN species are 
presented in Fig. 7. As can be seen, both $\mathrm{CO}$ and $\mathrm{CN}$ do not ionize near the stagnation region, but further along the body of the vehicle. This is an important observation as this ionization translates to a reduction of the $\mathrm{CN} / \mathrm{CO}$ concentration along the body, which is likely to affect the comparison to the Echelle measurements (as seen in the next subsection). Finally, Fig. 8 presents the electron distribution as well as the $\mathrm{C}^{+}$distribution. As with the other species, ionized $\mathrm{C}$ reaches its greatest concentration along the body, and not in the stagnation region, as is the case with $\mathrm{O}^{+}$and $\mathrm{N}^{+}$. The overall ion distribution can be evaluated by looking at the distribution of electrons. It is noted that $\mathrm{H}^{+}$, the only ion not presented in these graphs, only exists with a negligible concentration.

\section{Radiative heat flux}

Certain species present in the boundary layer are strong radiative emitters, and are expected to significantly contribute to the overall radiative heat flux at the surface. For the Stardust re-entry vehicle, the contribution of the radiative heat flux to the overall heat flux has been evaluated, at maximum intensity, to be approximately $10 \% .^{26}$

A radiative emission calculation is performed using the flow field solution of the $42 \mathrm{~s}$ trajectory point (71 $\mathrm{km}$ ), with the NEQAIR (version 99d) ${ }^{13}$ non-equilibrium radiation code. Apart from the usual air species, radiative emission from the $\mathrm{CN}$ violet and $\mathrm{CN}$ red systems is included.

The temperatures and species concentrations used as inputs to NEQAIR are presented in Fig. 9. Because the Echelle data has no spatial resolution, the computed spectra need to be spatially averaged over the front surface, using multiple lines parallel to the symmetry line. The lines used are located at $\mathrm{r}=0,0.2,0.3$ and $0.42 \mathrm{~m}$. The last line does not intersect with the surface, which explains why the temperatures are not at equilibrium on the right-hand side of Fig. 9g), and why Fig. 9h) does not have the same general behavior as the other density plots. Since the observation took place far away from Stardust, and the radiation is mostly emitted from the volumetric plasma in front of the vehicle and not from the surface, there is no need to account for the observation angle from which the data was acquired. It is noted, however, that it is preferable to factor in that angle of observation if more than the forebody of the vehicle is modeled, as a significant part of the plasma might be obstructed by the vehicle in that case, and therefore not in the line of sight of the instruments.

From the density plots presented in Fig. 9, it is interesting to note that $\mathrm{CN}^{+}$plays a more significant role in the determination of the species concentrations than was previously thought. It is created at the cost of $\mathrm{CN}$, and therefore reduces the $\mathrm{CN}$ concentration by up to two orders of magnitude in a region where the vibrational-electron-electronic temperature is high. The same cannot be said about $\mathrm{CO}^{+}$, as nowhere in the flow is that molecule present in quantities that approach the concentration of CO.

A comparison of the spectral emission from CN is presented in Fig. 10. In order to assess the importance of kinetic rates on radiation modeling, three different flow field simulations are used. The first one (labeled "Andersson") is considered the baseline, and uses the chemistry model detailed in Ref. 14. The second one (labeled "Park") uses the the kinetic rates of Ref. 30, which were devised for Mars re-entry, and therefore tailored for high temperature. The last one, labeled "All Andersson" uses all of the kinetics rates of the $\mathrm{CN} / \mathrm{NO}$ reduced model presented in Ref. 31.

It can be seen in that figure that the spectral computations match the Echelle data remarkably well, as the values are all within the same order of magnitude. The Park kinetic model appears to give better results than both of the Andersson models. However, all results are quite close to the experimental data, and when one factors in all the assumptions that are made during the entire modeling process, no definitive recommendation can be made as to which rates to use. The interesting part, however, is that there are some noticeable differences in the predicted $\mathrm{CN}$ spectral intensity when the $\mathrm{CN} / \mathrm{CO}$ exchange reaction is modified.

Finally, the radiative heat flux was computed for the three cases. For all three set of reaction rates, the total radiative flux is approximately $1 \%$ of the convective heat flux, making it negligible at this trajectory point. What is more important to acknowledge, however, is that a large portion (30-40\%) of the radiative heat flux is generated by $\mathrm{CN}$ over the wavelength range of the Echelle instrument (about 360 to $890 \mathrm{~nm}$ ).

\section{Conclusion}

As part of a continuing project to improve heat transfer and ablation rate modeling for hypersonic reentry vehicles, a comprehensive chemistry model for computing the flow around a re-entry vehicle using 


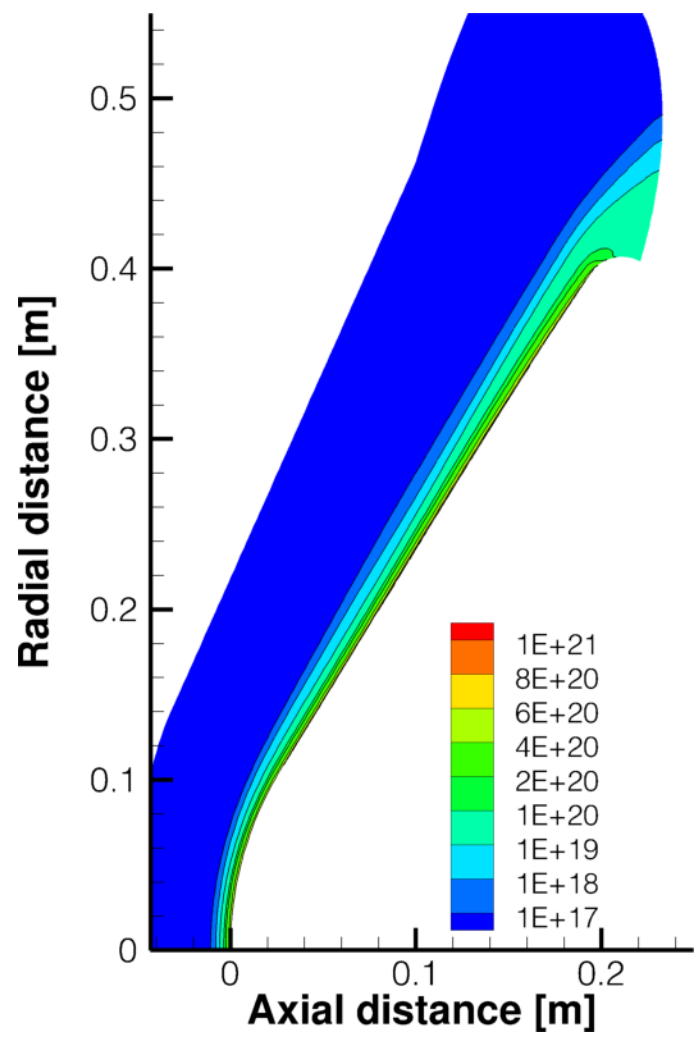

(a) $\mathrm{C}$

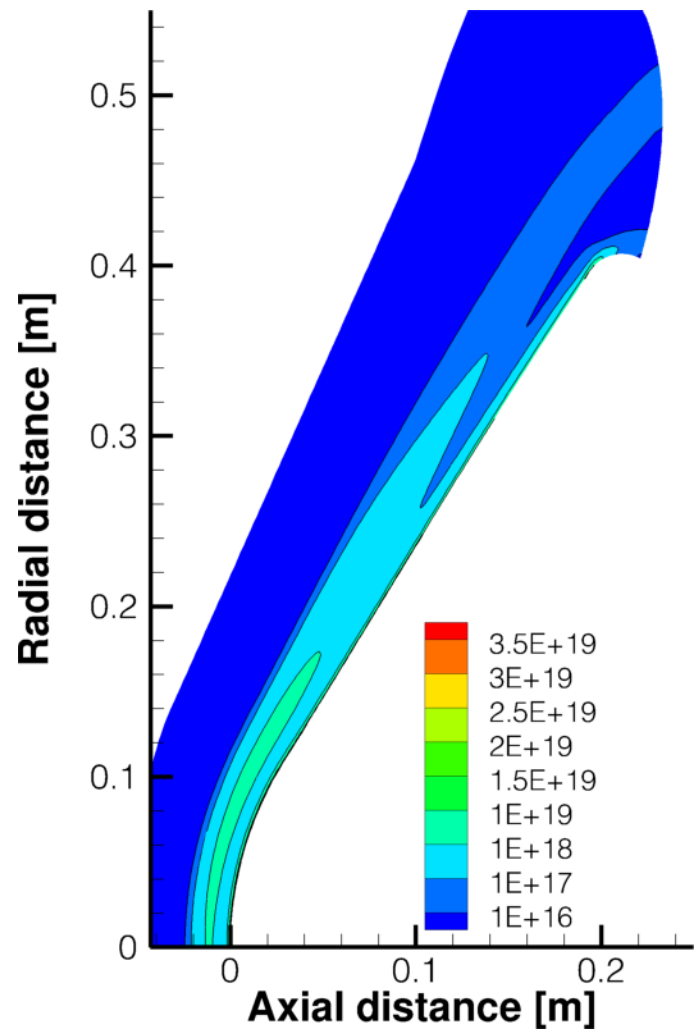

(c) $\mathrm{NH}$

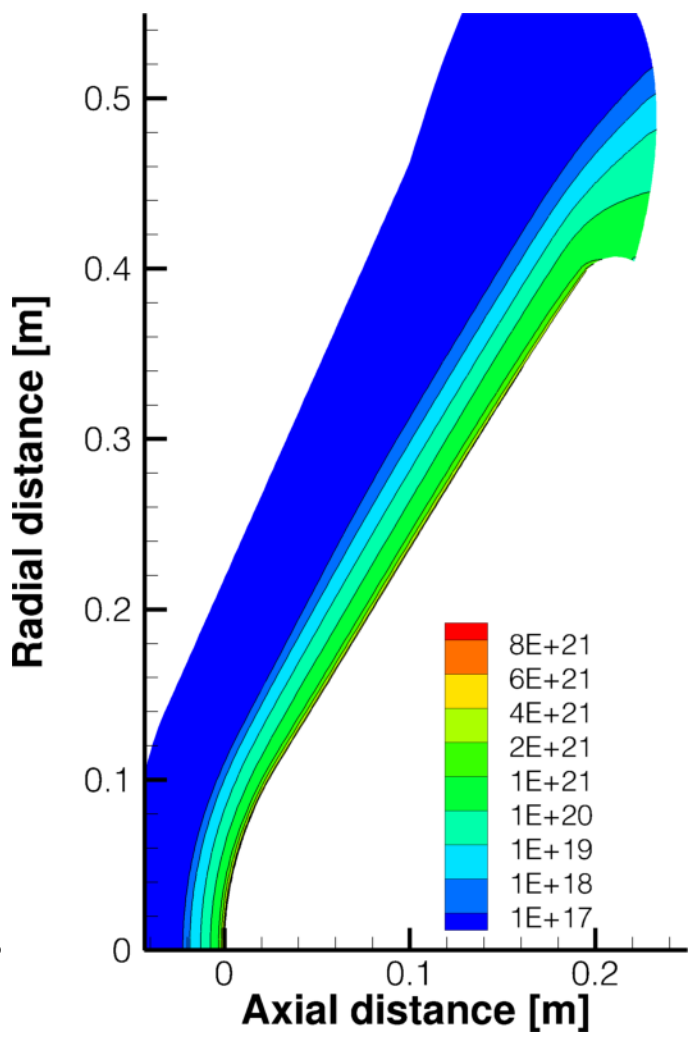

(b) $\mathrm{H}$

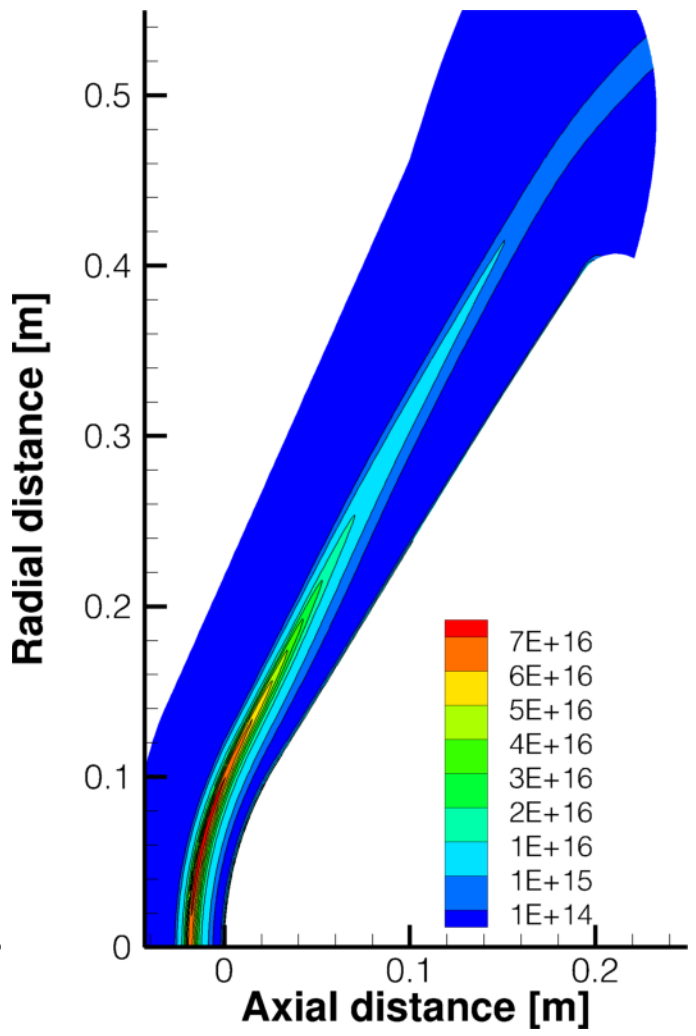

(d) $\mathrm{HNO}$

Figure 6. Species concentration $\left(\mathrm{m}^{-3}\right)$ isolines for the Stardust vehicle at $42 \mathrm{~s}$ into re-entry $(71 \mathrm{~km})$ 


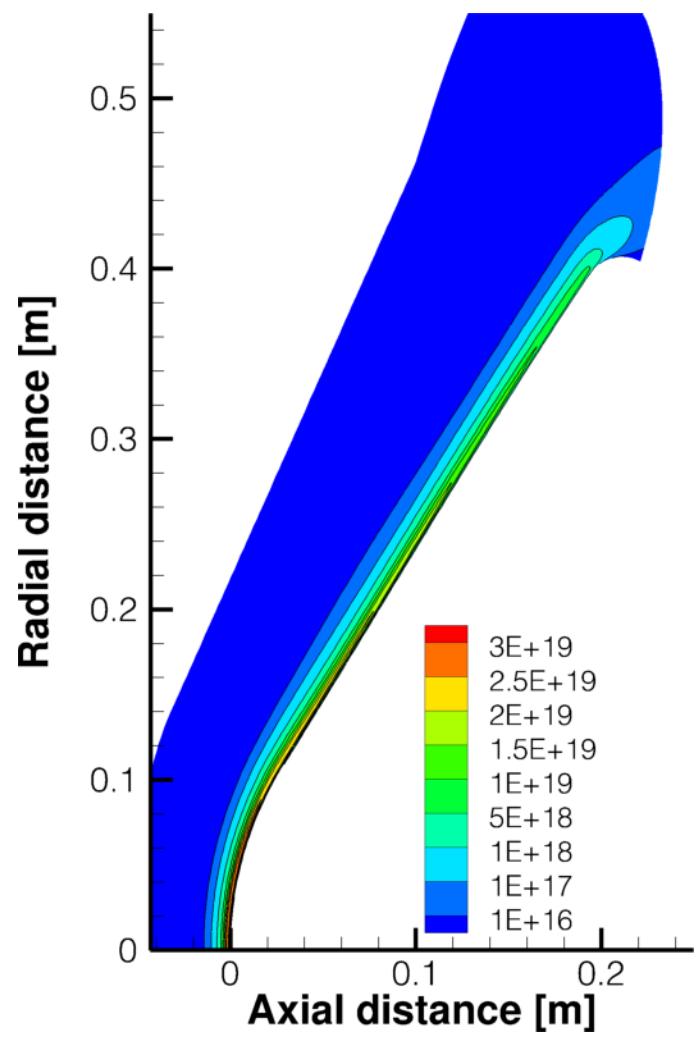

(a) $\mathrm{CN}$

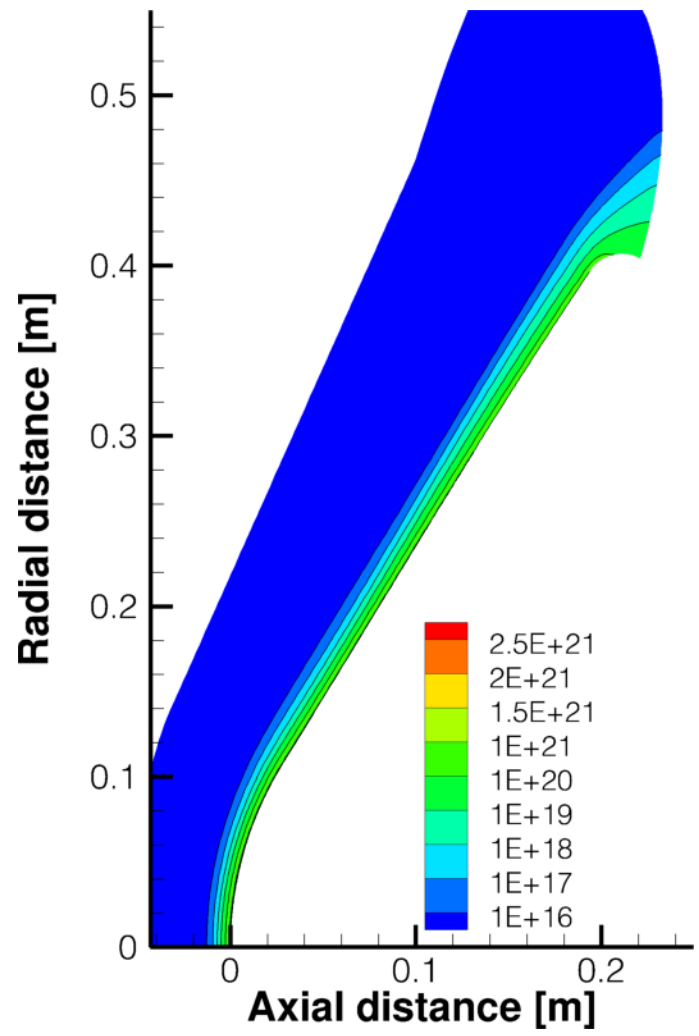

(c) $\mathrm{CO}$

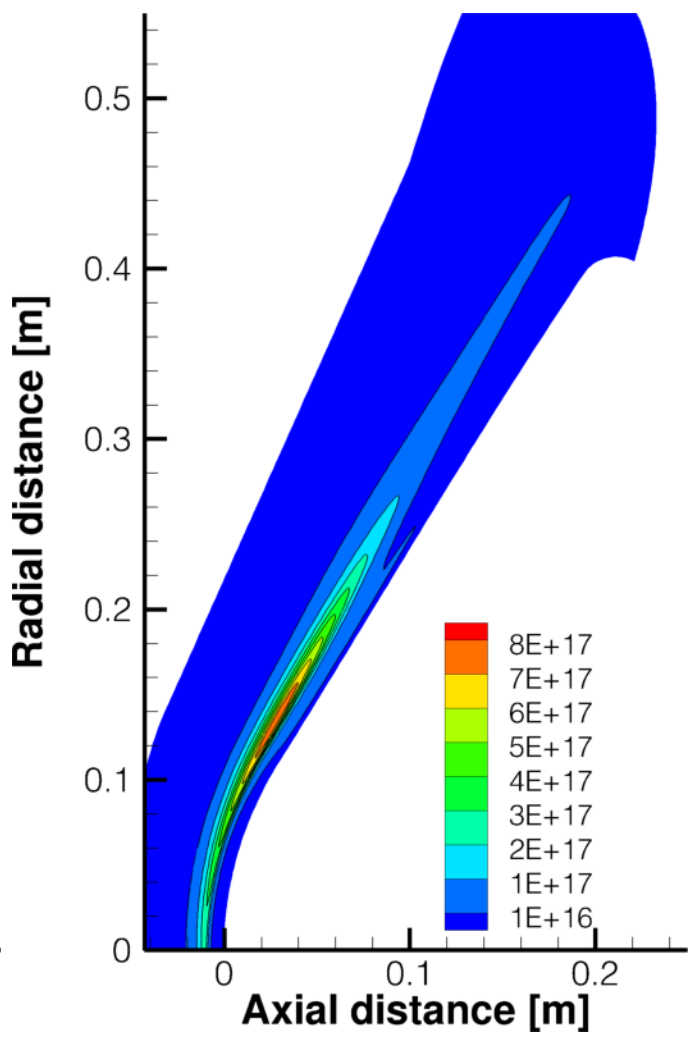

(b) $\mathrm{CN}^{+}$

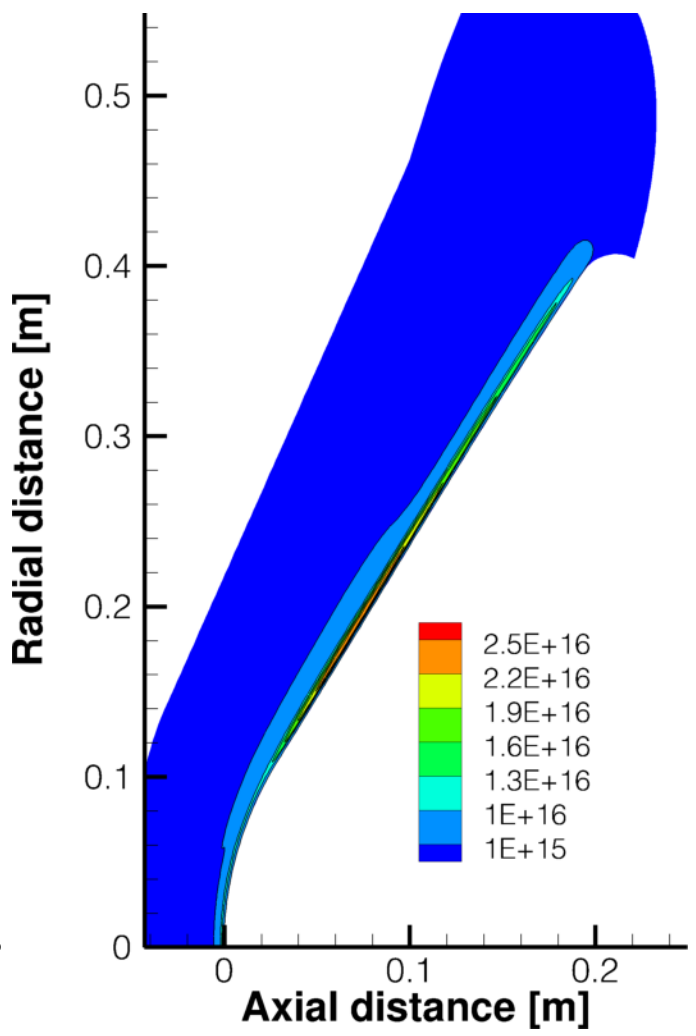

(d) $\mathrm{CO}^{+}$

Figure 7. Species concentration $\left(\mathrm{m}^{-3}\right)$ isolines for the Stardust vehicle at $42 \mathrm{~s}$ into re-entry $(71 \mathrm{~km})$ 


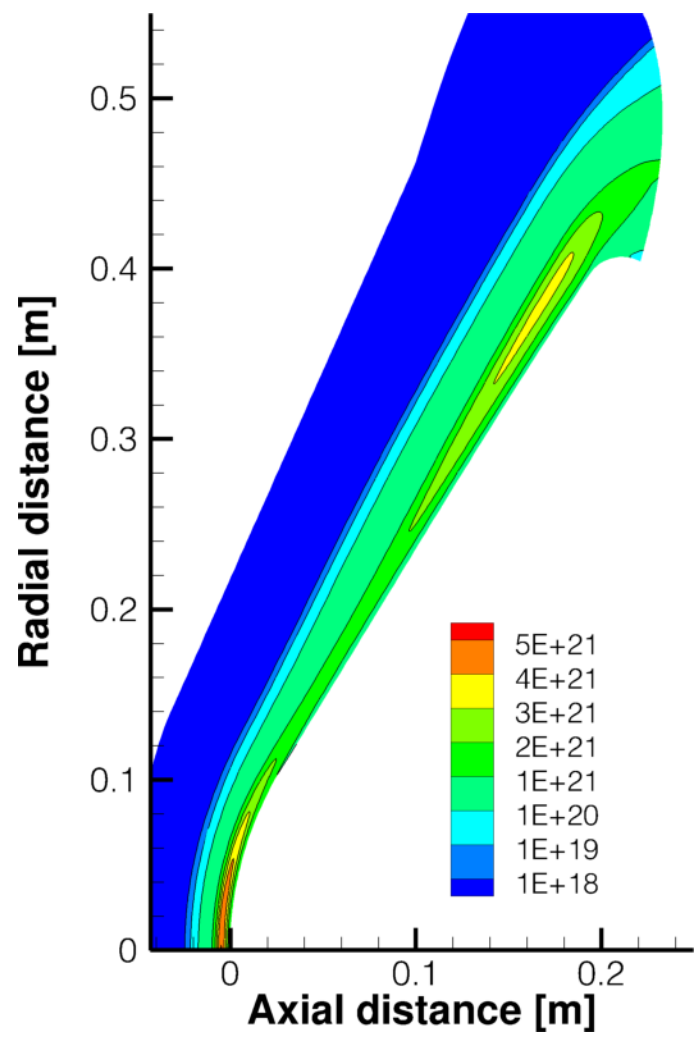

(a) $\mathrm{e}^{-}$

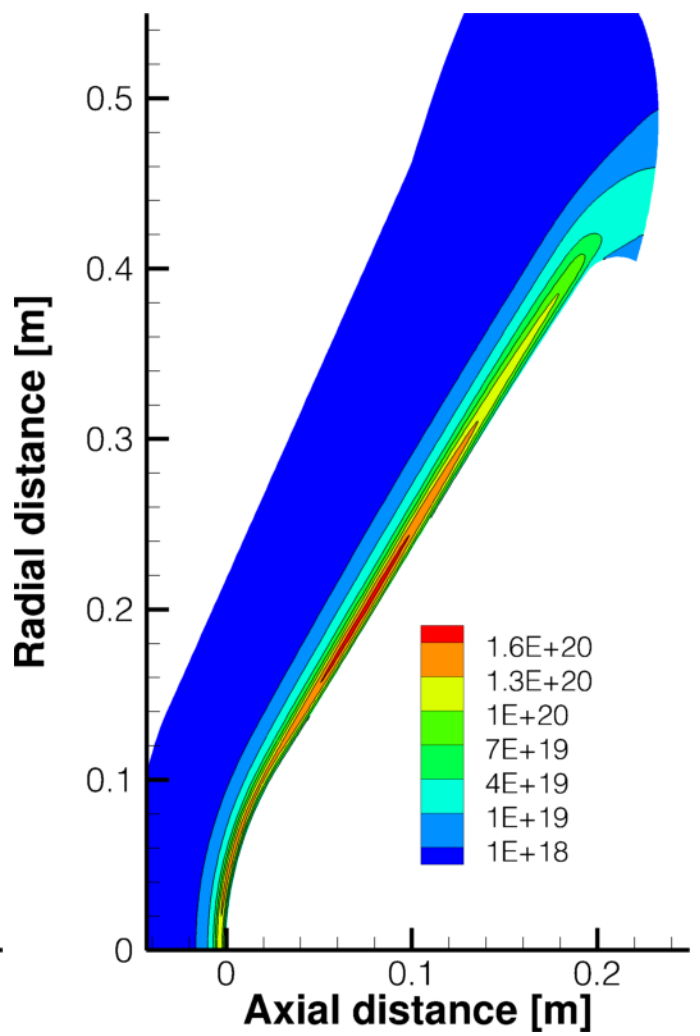

(b) $\mathrm{C}^{+}$

Figure 8. Species concentration $\left(\mathrm{m}^{-3}\right)$ isolines for the Stardust vehicle at $42 \mathrm{~s}$ into re-entry $(71 \mathrm{~km})$ 


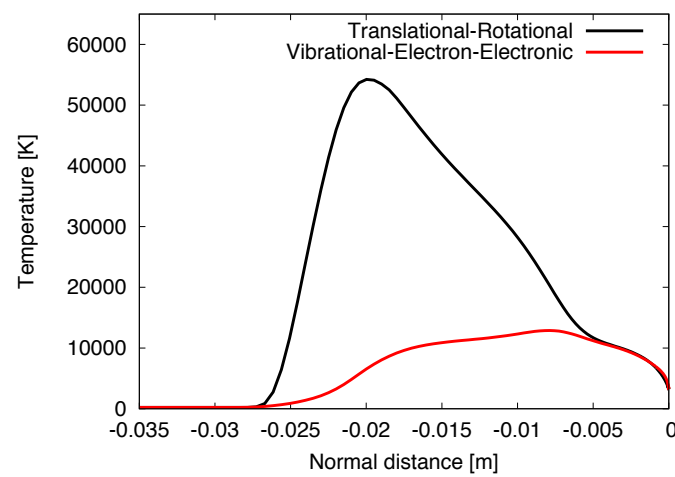

(a) Temperatures $(r=0.0 \mathrm{~m})$

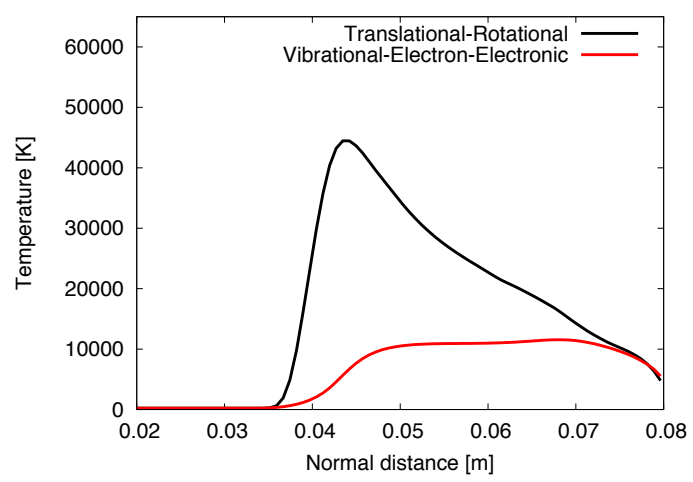

(c) Temperatures $(r=0.2 \mathrm{~m})$

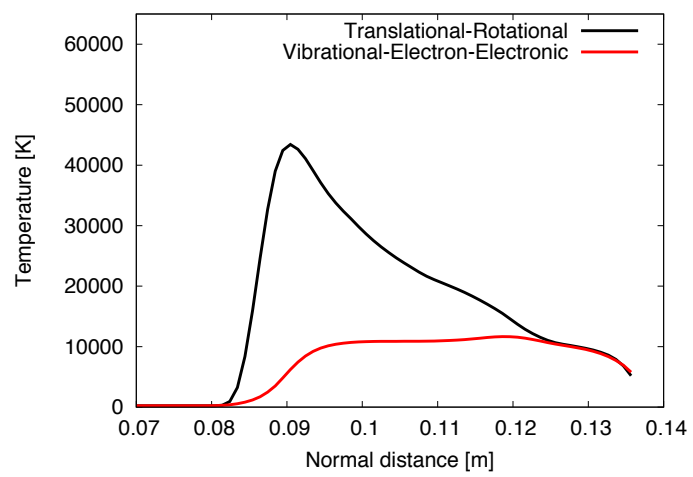

(e) Temperatures $(r=0.3 \mathrm{~m})$

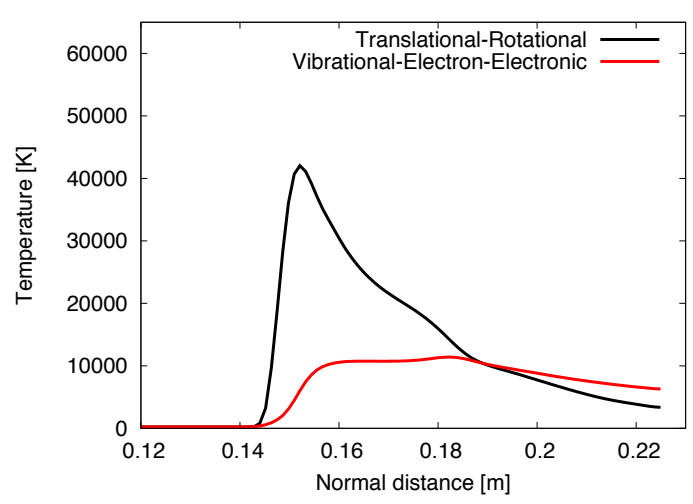

(g) Temperatures $(r=0.42 \mathrm{~m})$

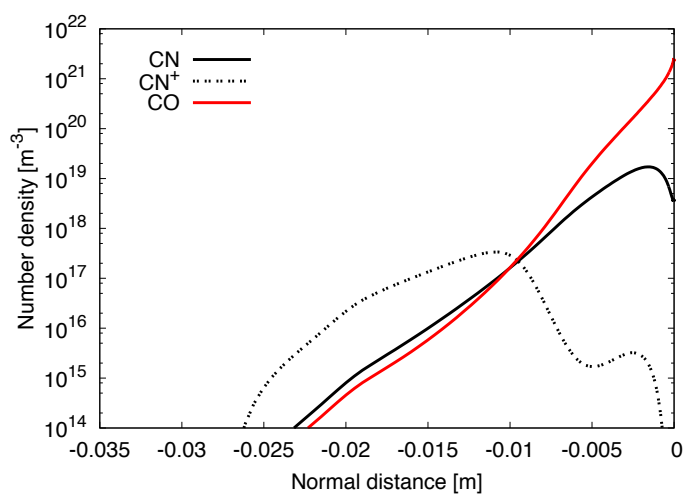

(b) Radiating species from ablation $(r=0.0 \mathrm{~m})$

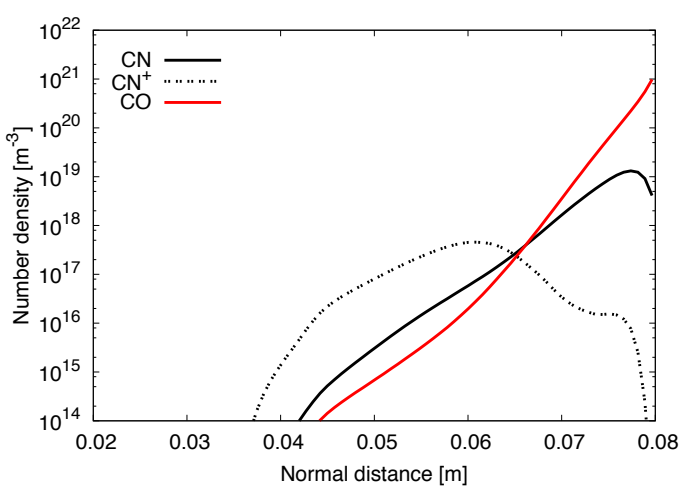

(d) Radiating species from ablation $(r=0.2 \mathrm{~m})$

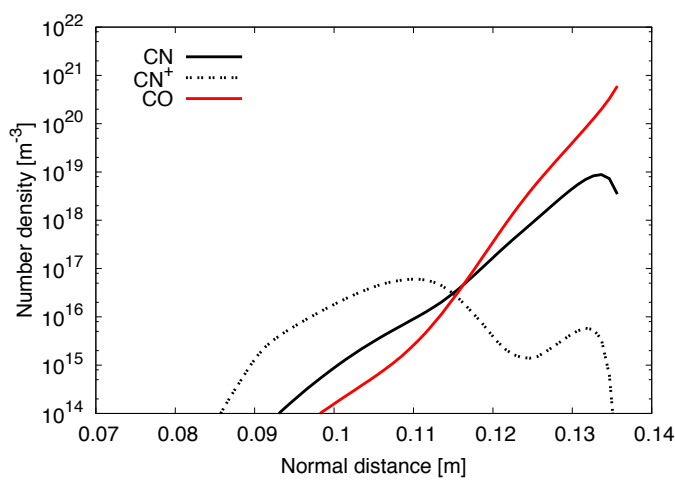

(f) Radiating species from ablation $(r=0.3 \mathrm{~m})$

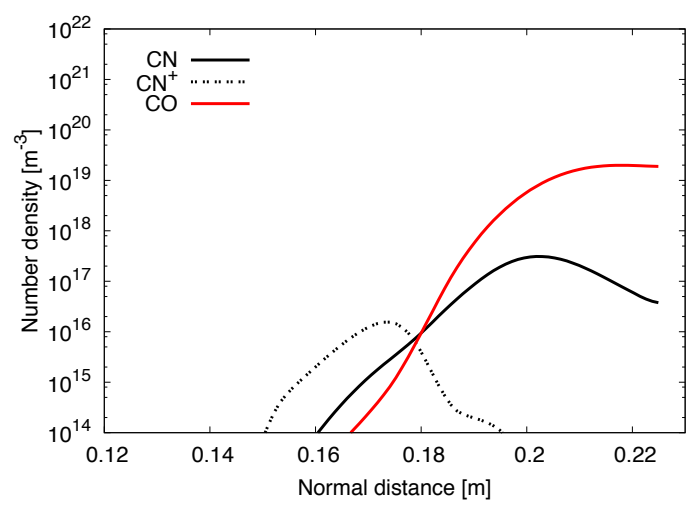

(h) Radiating species from ablation $(r=0.42 \mathrm{~m})$

Figure 9. Temperatures and radiating species concentrations along four parallel lines for the Stardust vehicle at $42 \mathrm{~s}$ into re-entry $(71 \mathrm{~km})$. Park's rate is used for the $\mathrm{CN} / \mathrm{CO}$ exchange reaction. 


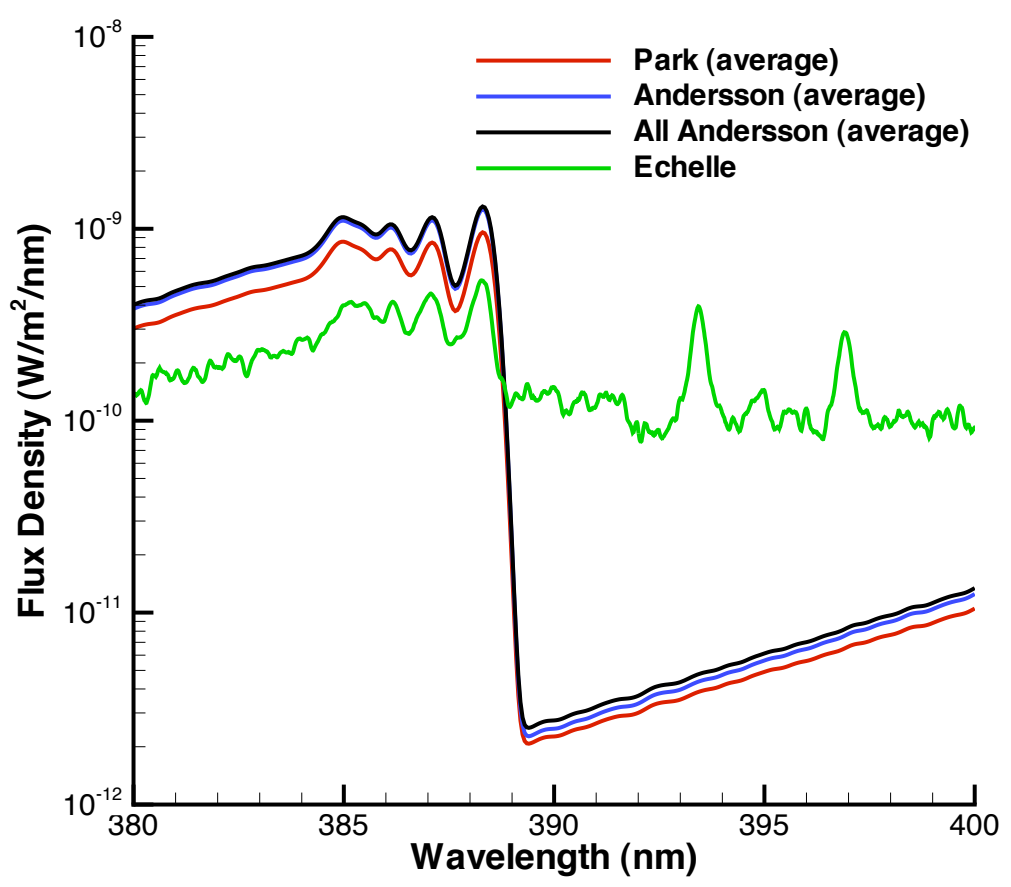

Figure 10. Comparison of the CN spectral line for the Stardust re-entry vehicle at 42 seconds $(71 \mathrm{~km})$

an ablative heat shield has been tested in a CFD code. The species used in the model were selected with careful consideration of the flow physics, and the reactions were evaluated and chosen from various sources in the literature. The model was reduced to a more manageable number of species and reactions, using a zero-dimensional sensitivity analysis, and was validated using various experimental results

In an attempt to assess the importance of accounting for ablation species in the flowfield, the chemistry set was implemented in the hypersonic non-equilibrium CFD code LeMANS, and used to model the Stardust vehicle at the $42 \mathrm{~s}$ trajectory point of its re-entry $(71 \mathrm{~km})$. This point was chosen because it is well into the continuum regime, and experimental data is available in the form of spectral radiative emission gathered by the Echelle instrument. As expected, the convective heat flux predicted using the carbon-phenolic-in-air chemistry model was significantly reduced relative to the prediction obtained using the equilibrium radiative boundary conditions. The species concentrations along the stagnation line were also presented and it was shown that at chemical equilibrium conditions, most species blown from the surface immediately react in the flowfield and are transformed. These results clearly indicate the need to use an appropriate chemistry model in the flow field, and that the chemistry model should be significantly different than that used to model pyrolysis gas behavior inside the TPS. Also, it was noted that the main heat flux reduction phenomenon occurs in the mass diffusion component, and not in the translational-rotational conduction component, as was the case at a higher altitude trajectory point.

Finally, the flow field solution was used to perform analysis of the CN radiative spectral emission using NEQAIR. The result was compared to the experimental data obtained by the Echelle instrument, and some kinetic rates used in the flow field chemistry model were modified to evaluate their effect on the spectral intensity of emitted radiation. Although the use of different kinetic rates translated into a discrepancy in the predicted spectral emission, the difference was not significant enough to give a formal recommendation as to which rates were more appropriate. Nevertheless, the computed results were very close to the observed values, which provides increased confidence in the proposed chemistry model. 


\section{Acknowledgments}

Financial support for this work was provided in part by NASA SBIR Phase-1 Award NNX10CC53P as well as through NASA Prime Contract NNA04BC25C to ELORET Corporation. The authors would also like to thank Dr. Mike Wright, Dr. Ioana Cozmuta, Dr. David Hash, Dr. Nagi Mansour, Dr. Mike Barnhardt, Dr. Jean Lachaud and Dr. Tahir Gökçen from NASA Ames Research Center for numerous insightful discussions.

\section{References}

${ }^{1}$ Suzuki, T., Sawada, K., Yamada, T., and Inatani, Y., "Experimental and Numerical Study of Pyrolysis Gas Pressure in Ablating Test Piece," Journal of Thermophysics and Heat Transfer, Vol. 19, No. 3, July-September 2005, pp. $266-272$.

${ }^{2}$ Dec, J. A. and Braun, R. D., "An Approximate Ablative Thermal Protection System Sizing Tool for Entry System Design," 44th AIAA Aerospace Sciences Meeting and Exhibit, No. AIAA 2006-780, Reno, NV, 9-12 January 2006.

${ }^{3}$ Ayasoufi, A., Rahmani, R. K., Cheng, G., Koomullil, R., and Neroorkar, K., "Numerical Simulation of Ablation for Reentry Vehicles," 9th AIAA/ASME Joint Thermophysics and Heat Transfer Conference, No. AIAA 2006-2908, San Francisco, CA, June 5-8 2006.

${ }^{4}$ Amar, A. J., Blackwell, B. F., and Edward, J. R., "One-Dimensional Ablation with Pyrolysis Gas Flow Using a Full Newton's Method and Finite Control Volume Procedure," 39th AIAA Thermophysics Conference, No. AIAA-2007-4535, Miami, FL, 25-28 June 2007, p. 41.

${ }^{5}$ Milos, F. and Chen, Y.-K., "Two-Dimensional Ablation, Thermal Response and Sizing Program for Pyrolyzing Ablators," 46th AIAA Aerospace Sciences Meeting and Exhibit, AIAA-2008-1223, Reno, NV, Jan. 7-10 2008, p. 7.

${ }^{6}$ Venkatachari, B. S., C.Cheng, G., P.Koomullil, R., and Ayasoufi, A., "Computational Tools for Re-entry Aerothermodynamics - Part II. Surface Ablation," 46th AIAA Aerospace Sciences Meeting and Exhibit, AIAA-2008-1218, Reno, NV, Jan. 7-10 2008.

${ }^{7}$ Martin, A. and Boyd, I. D., "Simulation of pyrolysis gas within a thermal protection system," 40th AIAA Thermophysics Conference, No. AIAA-2008-3805, Seattle, WA, June 23-26 2008, p. 20.

${ }^{8}$ Park, C., Jaffe, R. L., and Partridge, H., "Chemical-Kinetic Parameters of Hyperbolic Earth Entry," Journal of Thermophysics and Heat Transfer, Vol. 15, No. 1, January- March 2001, pp. 76-90.

${ }^{9}$ Suzuki, K., Kubota, H., Fujita, K., and Abe, T., "Chemical nonequilibrium ablation analysis of MUSES-C super-orbital reentry capsule," 32nd AIAA Thermophysics Conference, No. AIAA-1997-2481, June 23-25 1997.

${ }^{10}$ Olynick, D., Chen, Y.-K., and Tauber, M. E., "Aerothermodynamics of the Stardust Sample Return Capsule," Journal of Spacecraft and Rockets, Vol. 36, No. 3, May-June 1999, pp. 442-462.

${ }^{11}$ Martin, A., Boyd, I. D., Cozmuta, I., and Wright, M. J., "Chemistry model for ablating carbon-phenolic material during atmospheric re-entry," 48th AIAA Aerospace Sciences Meeting and Exhibit, No. AIAA-2010-1175, Orlando, FL, January 2010.

${ }^{12}$ Martin, A. and Boyd, I. D., "Assessment of carbon-phenolic-in-air chemistry models for atmospheric re-entry," 10th AIAA/ASME Joint Thermophysics and Heat Transfer Conference, No. AIAA-2010-4656, Chicago, IL, June 28th to July 1st 2010.

${ }^{13}$ Whiting, E. E., Park, C., Liu, Y., Arnold, J. O., and Paterson, J. A., "NEQAIR96, Nonequilibrium and Equilibrium Radiative Transport and Spectra Program: User's Manual," Reference Publication 1389, NASA, December 1996.

${ }^{14}$ Martin, A. and Boyd, I. D., "CFD Implementation of a novel carbon-phenolic-in-air chemistry model for atmospheric re-entry," 49th AIAA Aerospace Sciences Meeting and Exhibit, No. AIAA 2011-143, Orlando, FL, January 4-7 2011.

${ }^{15}$ Kee, R. J., Rupley, F. M., Miller, J. A., Coltrin, M. E., Grcar, J. F., Meeks, E., Moffat, H. K., Lutz, A. E., Dixon-Lewis, G., Smooke, M. D., Warnatz, J., Evans, G. H., Larson, R. S., Mitchell, R. E., Petzold, L. R., Reynolds, W. C., Caracotsios, M., Stewart, W. E., Glarborg, P., Wang, C., McLellan, C. L., Adigun, O., Houf, W., Chou, C. P., Miller, S. F., Ho, P., Young, P. D., Young, D. J., Hodgson, D. W., Petrova, M. V., and Puduppakkam, K. V., "CHEMKIN, Release 4.1," 2006.

${ }^{16}$ Scalabrin, L. C. and Boyd, I. D., "Numerical Simulations of the FIRE-II Convective and Radiative Heating Rates," 39th AIAA Thermophysics Conference, No. AIAA-2007-4044, Miami, FL, 25 - 28 June 2007, p. 17.

${ }^{17}$ Scalabrin, L. C., Numerical Simulation of Weakly Ionized Hypersonic Flow Over Reentry Capsules., Ph.D. thesis, The University of Michigan, Ann Arbor, MI, 2007.

${ }^{18}$ Scalabrin, L. C. and Boyd, I. D., "Development of an Unstructured Navier-Stokes Solver for Hypersonic Nonequilibrium Aerothermodynamics," 38th AIAA Thermophysics Conference, No. AIAA-2005-5203, Toronto, Ontario, June 6-9 2005, pp. $1-18$.

${ }^{19}$ Scalabrin, L. C. and Boyd, I. D., "Numerical Simulation of Weakly Ionized Hypersonic Flow for Reentry Configurations," 9th AIAA/ASME Joint Thermophysics and Heat Transfer Conference, No. AIAA-2006-3773, San Francisco, CA, June 5-8 2006 , p. 18.

${ }^{20}$ Holman, J. P., Heat transfer, Mc Graw-Hill : Publishing Company, 1990.

${ }^{21}$ Wright, M. J., Candler, G. V., and Bose, D., "Data-Parallel Line Relaxation method for the Navier-Stokes equations," AIA A Journal, Vol. 36, No. 9, September 1998, pp. 1603-1609.

${ }^{22}$ Gnoffo, P. A., "Upwind-Biased, Point-implicit Relaxation Strategies for Viscous Hypersonic Flows," 9th AIAA Computational Fluid Dynamics Conference, No. AIAA-1989-1972-CP, Buffalo, NY, June 13-15 1989, pp. 415-425.

${ }^{23}$ Martinelli, S. and Ruffin, S., "Validation Process for Blowing and Transpiration-Cooling in DPLR," 39th AIAA Thermophysics Conference, No. AIAA-2007-4255, 2007, p. 9.

${ }^{24}$ Thompson, R. A. and Gnoffo, P. A., "Implementation of a Blowing Boundary Condition in the LAURA Code," 46th AIAA Aerospace Sciences Meeting and Exhibit, No. AIAA-2008-1243, Reno, NV, Jan. 7-10 2008, p. 11. 
${ }^{25}$ Martin, A. and Boyd, I. D., "Implicit implementation of material response and moving meshes for hypersonic re-entry ablation," 47th AIAA Aerospace Sciences Meeting and Exhibit, No. AIAA-2009-0670, Orlando, FL, Jan. 5-8 2009.

${ }^{26}$ Trumble, K. A., Cozmuta, I., Sepka, S., and Jenniskens, P., "Post-flight Aerothermal Analysis of the Stardust Sample Return Capsule," 46th AIAA Aerospace Sciences Meeting and Exhibit, AIAA-2008-1201, Reno, NV, Jan. 7-10 2008.

${ }^{27}$ NASA Ames Research Center, DPLR Package Users Guide, 3rd ed.

${ }^{28}$ Chen, Y.-K. and Milos, F. S., "Ablation and Thermal Response Program for Spacecraft Heatshield Analysis," Journal of Spacecraft and Rockets, Vol. 36, No. 3, May-June 1999, pp. 475-483.

${ }^{29}$ Milos, F. S. and Chen, Y.-K., "Comprehensive model for multicomponent ablation thermochemistry," 35th Aerospace Sciences Meeting and Exhibit, No. AIAA-1997-141, Reno, NV, Jan. 6-9 1997, p. 9.

${ }^{30}$ Park, C., Howe, J. T., Jaffe, R. L., and Candler, G. V., "Review of Chemical Kinetic Problems of Future NASA Missions, II: Mars Entries," Journal of Thermophysics and Heat Transfer, Vol. 8, No. 1, March 1994, pp. 9-23.

${ }^{31}$ Andersson, S., Markovic, N., and Nyman, G., "Computational Studies of the Kinetics of the C $+\mathrm{NO}$ and $\mathrm{O}+\mathrm{CN}$ Reactions," J. Phys. Chem. A, Vol. 107, 2003, pp. 5439-5447. 